\title{
Towards More Meaningful Measures in Healthcare
}

\author{
S Leeder, L Russell and A Beaton
}

\section{Abstract}

Most health systems continue to be restructured and modified without much thought to underlying public policy. Patient safety, quality and innovation are monitored through a range of agencies while performance measures are regularly measured and the results published. Primary healthcare in many systems remains fragmented. To achieve value of the whole health system as well as its component parts, the development of an outcomes-based approach to performance measurement is required to guide the delivery of constantly improving health services. This is a critical issue in health systems management.

Abbreviations: KPI - Key Performance Indicator; SLM - System Level Measures.

Key words: health outcomes; primary care; system level measures.
Stephen Leeder AO, MD, PhD, FRACP, FAFPHM Professor of Public Health and Community Medicine Menzies Centre for Health Policy

The University of Sydney

Chair Western Sydney Local Health District Board

Director Research Network

Western Sydney Local Health District

Sydney, New South Wales, Australia

\section{Lesley Russell}

Adjunct Associate Professor, Sydney Medical School

Honorary Associate

Menzies Centre for Health Policy

The University of Sydney

Sydney, New South Wales, Australia

\section{Angela Beaton $\mathrm{PhD}$}

Centre for Health and Social Practice

Te Kura Mō Ngā Mahi Tiaki I Te Hapori

Waikato Institute of Technology

Hamilton, New Zealand

Menzies Centre for Health Policy,

University of Sydney

Sydney, New South Wales, Australia

Correspondence:

Stephen.leeder@sydney.edu.au
Key performance indicator (KPI) data are used internationally to enable health system-wide quality improvement and reforms; and to measure the extent to which there is equity in health, access to healthcare and financing. [1] They can be applied to those who provide services to specify volume, style and cost and can link to other measures, both clinical and financial, of achievement and outcome. However, of themselves the vast majority of indicators concern processes of performance and sometimes its structural context, but rarely its ultimate outcome. [2] Moreover, in Australia attention has centred on KPIs for acute hospital specialty care rather than primary or continuing care, further limiting their clinical reach and utility. With new technology and expanding expectations of those who use and pay for services, the range of KPIs is widening, which is aided by the rapid expansion of information technique in health systems.

The place of KPIs in assessing the managerial machinery, clinical processes and financial performance of health systems is now deeply entrenched. KPIs pertaining to process and structure have, however, set the hares running - if we have KPIs for these things, why not for outcomes, life gained, and suffering relieved, or deterioration of the chronically ill patient prevented? If we decide that we value outcomes such as coordinating care for patients with serious and continuing illness or achieving health gain in the community through prevention, then KPIs will be 
required that tell us how well we are doing in achieving those outcomes. KPIs relating to the structure and process of care are insufficient.

KPIs relating to the prevailing general practice business models are generally similar to those that underpin activitybased funding in hospitals - they do not always measure achievement of the goals of patient-centred medical homes or community-controlled models of primary healthcare. [3] Indigenous providers are key players in the Indigenous community in exercising self-determination and improving health outcomes; therefore, it will be important for Indigenous providers to grow capability and capacity for data collection and analysis, because data will increasingly drive funding decisions moving forward. [4]

\section{The complex task of measuring outcomes}

The process of healthcare is generally judged to be valuable by most humane societies, though the proportion of their national treasure that they devote to healthcare varies greatly, as does the way in which it is spent and the extent of government versus private investment. But if the purpose of healthcare is held to be to improve the health of the public, then outcomes provide the information that can assure investors that the product matches their expectations. This becomes the central KPI. We can only be certain that efforts to improve health and the health system are well-directed if we measure the outcomes. [5]

For example, comprehensive primary care uses integrated, team-based services for those with complex and continuing multiple chronic disorders. This enables timely recognition and early intervention in acute deterioration with the intention of stopping it getting worse and cascading into a clinical disaster. To achieve this the system of care must be sensitive to patient/carer needs and perspectives [6] and these are critically important elements for which process and structure KPIs serve a valuable purpose. If we consider it important to focus efforts on equity within the health system, we will not be satisfied with performance indicators that do not reflect equity and accessibility of care. While public health has traditionally been more focused on equity issues, primary care, acute care, community care, longterm care - together with agencies, providers and service users - must be engaged in the process to implement indicators that are truly valuable.

\section{Performance indicator overload}

Currently there are mountain ranges of performance indicators and reporting requirements in Australia. ${ }^{1}$ There is an understandable tendency to measure what can easily be measured, which as often as not concerns process and activity rather than outcome - so many hernia operations this year, a certain percentage of patients presenting to emergency departments processed within four hours and so on. Many current performance indicators are bothersome obsessions with inconsequential processes, small details of financial management and risk management of mediasensitive matters that have little to do with health. Few indicators evaluate team work and transitions of care across sectors throughout the patient journey. KPIs easily become the Bitcoin of heroic power plays within the monumental bureaucracy of the average health service.

\section{What to do with the data}

What happens to the data that are collected from performance measurement? Over decades, much was warehoused or buried in a data cemetery. There is light, however - contemporary information technology systems in which these data are stored provide for the power of 'big data' analytics to come into play. While many of these data do not connect directly with health outcomes, action is taken on KPIs that relate to processes that in other settings have a strong connection to a health outcome, for example, with high-quality clinical practice guidelines.

Several questions remain for policy makers who are increasingly making use of the data collected for performance measurement. How are performance measures being used in practice? What types of system and outcomes changes have occurred as a result of information from these measures? What could facilitate the use of performance measures and the data they generate? What are, or should be, the consequences of poor performance? While there is no magic inherent in outcome data, appropriate publication of data has been shown to drive improvement. [7]

\section{International lessons for Australia}

In New Zealand it is accepted that measurement of health system performance and outcomes requires a systemlevel strategic framework. That includes an integrated data infrastructure across health and social systems with the ability to measure progress towards a reduction in health disparities among different population groups (utilising National Health Index numbers, a unique identifier that is assigned to every person who uses health and disability support services in New Zealand).

\footnotetext{
1 National Health Performance Framework, last updated in 2009; National Key Performance Indicators for Aboriginal and Torres Strait Islander Primary Healthcare; and A Set of Performance Indicators across the Health and Aged Care System, which was developed by the Australian Institute of Health and Welfare in 2008.
} 
For example, one measure of care integration is whether patients aged 75 years or more were admitted to acute care more than twice a year. [8] If high compared to a predetermined standard, this measure of the use of acute care bed days for a targeted group indicates that primary care (health and social supports) need to be reviewed for these patients.

In early 2016, New Zealand introduced System Level Measures (SLMs), or high-level goals for the health system. The measures were intended to show how the country's health and social welfare systems are performing and the value the country is receiving from them.

Each part of the system is important in determining how well the overall goal is met. For example, the measure 'acute hospital bed days per capita' above depends upon good primary care, discharge planning and communication between hospitals and community organisations; these linked local contributory measures contribute to the overall SLM.

Contributory measures for 'acute hospital bed days per capita' include acute readmissions, length of stay and influenza vaccinations in the elderly. The most important contributory measures to address can be chosen locally, based on the needs and priorities of local communities and health services, and local drivers of variation. [9] By identifying the correct contributory measures to address, and using quality improvement methods to improve their performance, the SLM should also improve.

There are many potential problems to be avoided. Lessons from the United Kingdom show that factors which help in the derivation, implementation and use of indicator systems include clear objectives, involvement of stakeholders in development, and use of 'soft' data to aid interpretation. [10] Major problems reported include: the availability, validity and reliability of data; confounding; problems with robustness, sensitivity and specificity; the potential for perverse incentives; and system gaming.

Finally, a recent report from the Kings Fund provides salient advice. [11] It pushes for 'intelligent transparency' with an emphasis on a tiered approach to indicators that might populate a local health system scorecard. It also reiterates the need for radical simplification and better alignment of the disparate performance assessment frameworks currently in use, thus consolidating several national outcomes frameworks into a single, coherent entity covering the NHS, public health and adult social care.

\section{Conclusions}

The current and proposed reforms to primary care services in Australia - including the coordinating and commissioning roles of Primary Health Networks, mental health reforms and Healthcare Homes - all require the concurrent development and implementation of meaningful performance measures to ensure improved patient and population health outcomes, equity and efficiency, value to taxpayers, information to inform policy, and greater transparency. Similar needs persist in the acute hospital sector.

Lessons from other countries with similar health systems show that integration of healthcare and social data is a complex and long-term enterprise and that it can benefit from specialist agency contributions that are at arm's length from government, independent, and well-resourced. Capacity and capability building in the use of big data is also essential for Indigenous providers to ensure funding decisions are evidence-based. Multiple opportunities are now presenting in abundance through the use of information technology to determine how we are doing in our primary goal of improving the health of the community and how we can continue to close the gap between Indigenous and nonIndigenous populations in Australia and internationally.

\section{Competing interests}

The authors declare that they have no competing interests.

\section{References}

1. Hibbert P, Hannaford N, Long J, Plumb J, Braithwaite J. Final Report: Performance indicators used internationally to report publicly on healthcare organisations and local health systems. Australian Institute of Health Innovation, University of New South Wales; 2013.

2. Ayanian JZ, Markel H. Donabedian's Lasting Framework for Healthcare Quality. N Engl J Med. 2016; 375:205-207. DOI: 10.1056/ NEJMp1605101.

3. Panaretto KS, Wenitong M, Button S, Ring IT. Aboriginal community controlled health services: leading the way in primary care. Med J Aust. 2014;200(11):649-652. DOI:10.5694/mja13.00005.

4. Penman-Aguilar A, Talih M, Huang D, Moonesinghe R, Bouye K, Beckles $G$. Measurement of health disparities, health inequities, and social determinants of health to support the advancement of health equity. J Public Health Manag Pract. 2016 Jan-Feb;22 Suppl 1:S33-42. doi: 10.1097/PHH.0000000000000373.

5. Alderwick H, Robertson R, Appleby J, Dunn P, Maguire D. Better value in the NHS: the role of changes in clinical practice. London: King's Fund; 2015.

6. Stange KC, Nutting PA, Miller WL. et al. Defining and measuring the patientcentred medical home. J Gen Intern Med. 2010; 25:601. doi:10.1007/s11606-010-1291-3.

7. Fung CH, Lim YW, Mattke S, Damberg C, Shekelle PG. Systematic review: the evidence that publishing patient care performance data improves quality of care. Ann Intern Med. 2008;148(2):111-23. 
8. Health Quality and Safety Commission New Zealand. Available: New health sector System Level Measures have quality improvement focus; 2016. Available: https://www.hqsc.govt.nz/our-programmes/ health-qualityevaluation/news-and-events/news/2500/

9. McDonald A. Case study: Harnessing data for local quality improvement in diabetes. Te Awakairangi Health Network (TeAHN): New Zealand; 2016. Available: https://www.hqsc.govt.nz/assets/ Health-Quality-Evaluation/PR/Case-study-TeAwakairangi-HealthNetwork-diabetes-Jan-2016.pdf

10. Freeman T. Using performance indicators to improve healthcare quality in the public sector: a review of the literature. Health Serv Manage Res. 2002;15(2):126-137. DOI: 10.1258/0951484021912897

11. Ham C, Raleigh V, Foot C, Robertson R, Alderwick H. Measuring the performance of local health systems: a review for the Department of Health. London: King's Fund; 2015. 